\title{
Instability of the Mediterranean Water undercurrents southwest of Portugal: effects of baroclinicity and of topography
}

\author{
Laurent CHERUBIN, Xavier CARTON *, Jérôme PAILlET, Yves MOREL, Alain SERPETTE \\ Centre militaire d'océanographie, Service hydrographique et océanographique de la Marine, 13, \\ rue du Chatellier, 29275 Brest, France
}

Received 7 December 1999; revised 28 March 2000; accepted 28 March 2000

\begin{abstract}
Southwest of Portugal, in situ data show that part of the mesoscale variability of the Mediterranean Water undercurrents is triggered by topographic effects (near capes and submarine canyons), and is driven by a dominantly baroclinic instability. The vertical alignment of these undercurrents observed at sites of eddy formation is indeed favorable to baroclinic instability. This instability is materialized by the formation of filaments and of small eddies in the Portimão canyon and of meddies near Cape Saint Vincent and near the Estramadura Promontory. Hydrological data and float trajectories reveal that these eddies have a baroclinic structure. Near Portimão canyon, the variation of the potential vorticity of the undercurrents again proves their sensitivity to baroclinic and also to barotropic instabilities, enhanced by the canyon. Finally, a model of stationary coastal current explains the variations of its horizontal structure over a canyon. (C) 2000 Ifremer/ CNRS/IRD/Éditions scientifiques et médicales Elsevier SAS
\end{abstract}

Résumé - Instabilité des sous-courants d'eau méditerranéenne au sud-ouest du Portugal : effets conjoints de la baroclinicité et de la topographie. Au sud-ouest du Portugal, des données in situ montrent qu'une partie de la variabilité méso-échelle des sous-courants d'eau méditerranéenne est déclenchée par des effets topographiques au voisinage des caps et des canyons sous-marins et est générée par une instabilité essentiellement barocline. L'alignement vertical de ces sous-courants, observé aux sites de formation de tourbillons, est en effet favorable à l'instabilité barocline. Cette instabilité est matérialisée par la formation de filaments et de petits tourbillons lenticulaires dans le canyon de Portimão, et de "meddies" au cap Saint Vincent et près du promontoire d'Estrémadure. Les données hydrologiques et les trajectoires de flotteurs lagrangiens révèlent que ces tourbillons ont une structure barocline. Près du canyon de Portimão, la variation de la vorticité potentielle des souscourants montre leur sensibilité à l'instabilité barocline, et également barotrope, amplifiées par le canyon. Enfin, un modèle de courant côtier stationnaire permet d'expliquer ses variations de structure horizontale sur un canyon. (C) 2000 Ifremer/CNRS/IRD/Éditions scientifiques et médicales Elsevier SAS

Mediterranean Water / undercurrents / baroclinic instability / meddies / NE Atlantic

Eau méditerranéenne / sous-courants / instabilité barocline / "meddies" / Atlantique nord-est

* Correspondence and reprints: xcarton@ifremer.fr (X. Carton).

(C) 2000 Ifremer/CNRS/IRD/Éditions scientifiques et médicales Elsevier SAS.

PII: S0399-1784(00)01105-1/FLA 


\section{INTRODUCTION}

The Service hydrographique et océanographique de la Marine (SHOM) conducted two oceanographic experiments in 1995 and 1997 in the Gulf of Cadiz and southwest of Portugal (Semane program). The aim of these cruises was to investigate the mesoscale variability of the Mediterranean Water undercurrents along the Iberian slope and the role played by submarine canyons in their instability.

These undercurrents originate in the Mediterranean Water which flows out of the Straits of Gibraltar into the Gulf of Cadiz. This salty and warm water plunges down the continental slope, mixes with the fresher Atlantic water via turbulent motions (O'Neil-Baringer and Price, 1997), and veers right, under the influence of the Coriolis force, to follow the Iberian slope northwestward (Madelain, 1970; Zenk, 1970). This outflow separates into two density currents, which reach their equilibrium depths (800 and $1200 \mathrm{~m}$ ) near $8^{\circ} \mathrm{W}$ (Zenk, 1975; Ambar and Howe, 1979). The upper current is warmer and the lower one saltier.

The instability of these currents has already been evidenced experimentally (Käse and Zenk, 1996), with in particular eddy formation near capes. These eddies of Mediterranean Water, called meddies, are large, anticyclonic, and subsurface (thermocline) intensified. The dynamical role of capes in vortex formation from a coastal current is now well established theoretically (Pichevin and Nof, 1996). This role is supported experimentally by observations of meddies east of Cape Saint Vincent (Swallow, 1969) and of the Estramadura Promontory (Zenk et al., 1992) (figure 1). Recently, meddies have been tracked for several

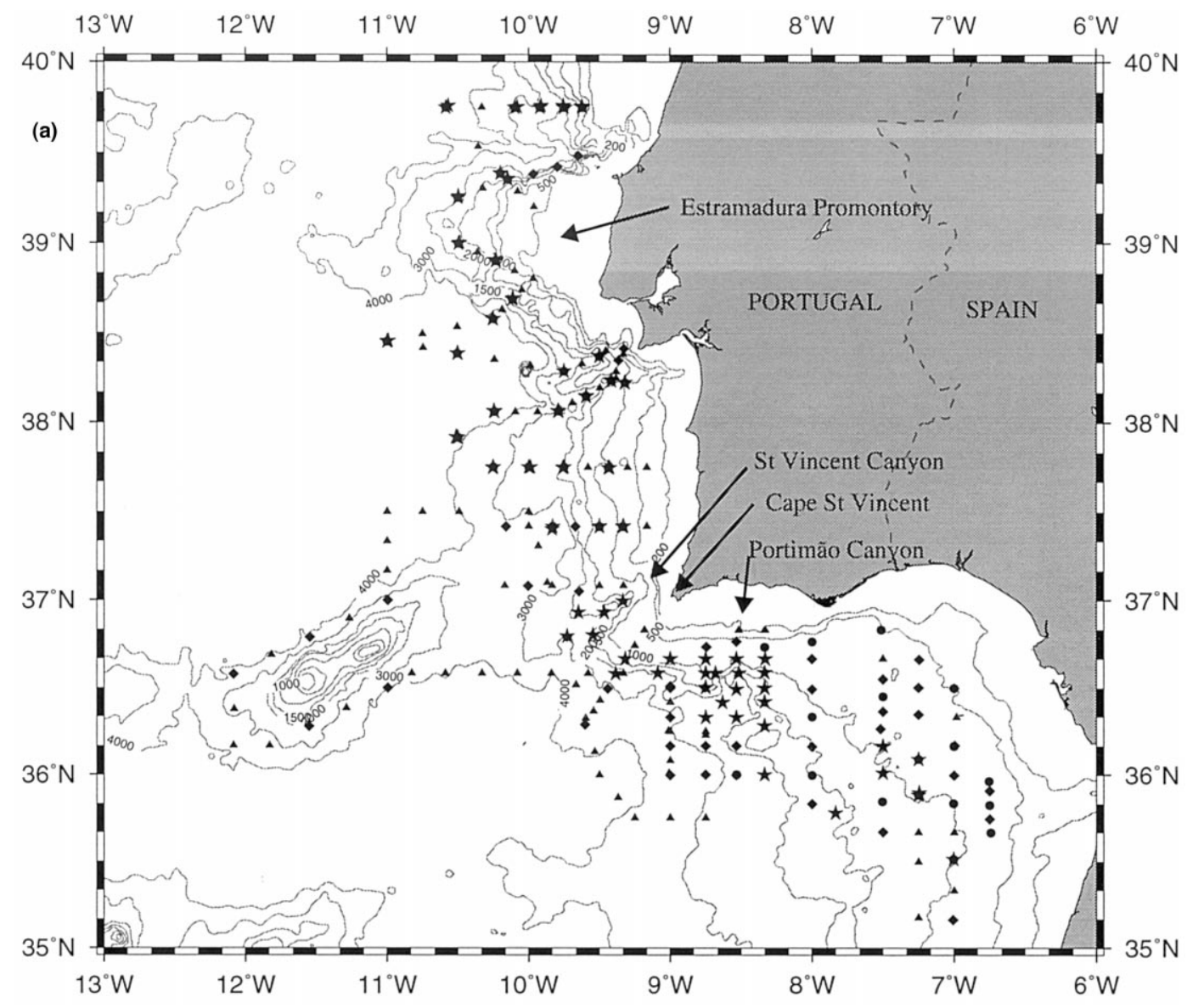

Figure 1. Experimental array of Semane 95 (a) and Semane 97 (b). Stars indicate CTD/LADCP soundings, circles are CTD stations with Niskin bottles, diamonds are XCTD casts and triangles are XBT casts. 


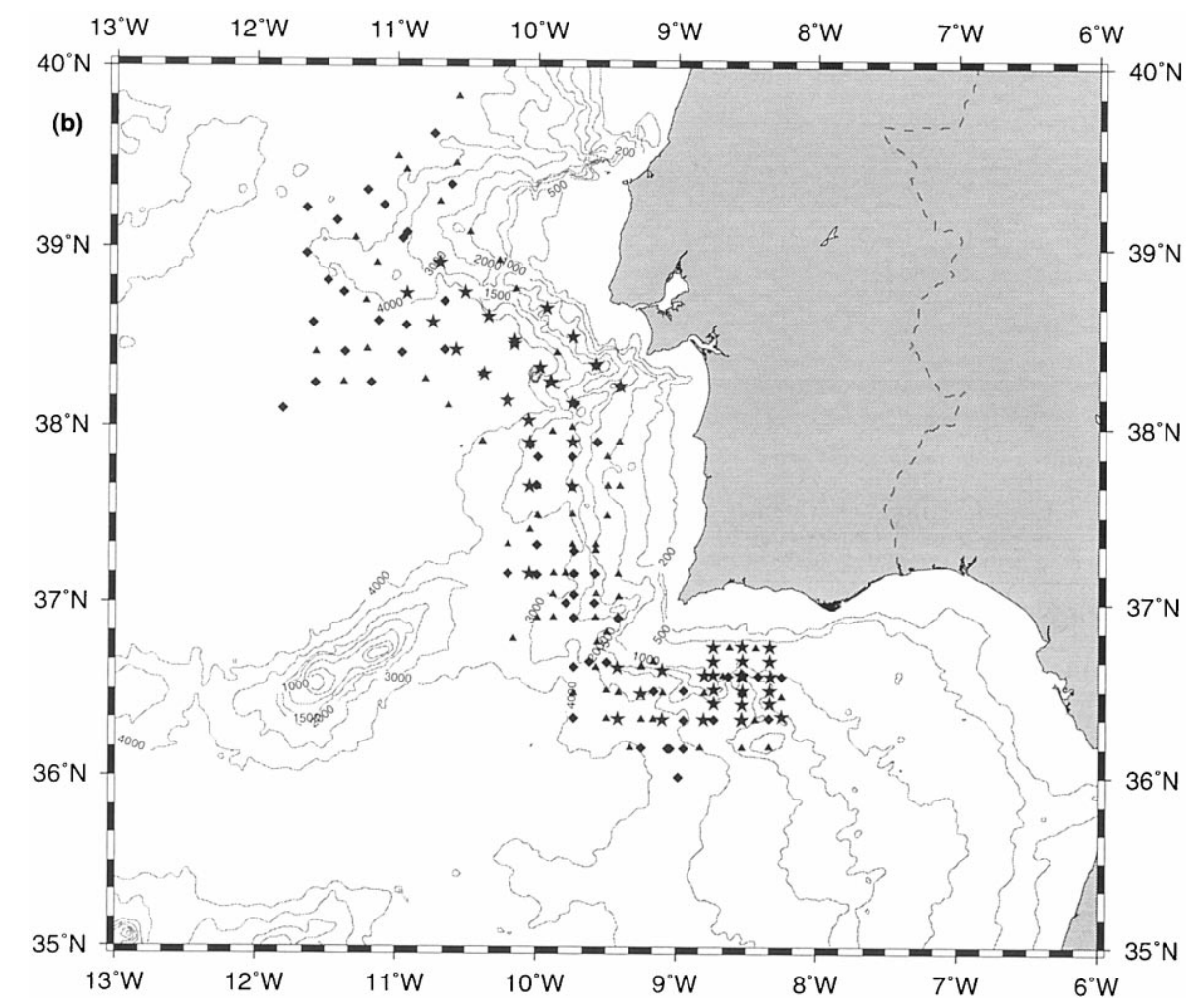

Fig. 1. (Continued)

months with Rafos floats (Bower et al., 1995), showing westward and southwestward trajectories from their formation sites (Zenk et al., 1992; Bower et al., 1997). This direction of propagation can be accounted for by the effects of the planetary vorticity gradient, of large-scale currents and of topography on anticyclonic vortices (Morel, 1995).

The Iberian continental shelf and slope are cut at many places by deep and narrow canyons. Theoretical studies prove that such canyons can destabilize coastal flows (e.g. Chérubin et al., 1996). Nevertheless, observations of such destabilization are not numerous: up to now, only one small eddy of Mediterranean Water has been observed between the longitudes of Portimão canyon and of Cape Saint Vincent (Prater and Sanford, 1994).

The present paper analyzes the Semane data to investigate the mechanisms underlying the instability of the Mediterranean water undercurrents, with emphasis on the effects of Portimão canyon. After presenting the data collection and processing, we describe the unstable events observed on the undercurrents in the Semane data; we find evidence for the nature of the instability and for the role of topography. It appears that this instability is amplified over the Portimão canyon; a theoretical model finally examines how a canyon perturbs the horizontal structure of a coastal current.

\section{MATERIAL AND METHODS}

\subsection{Data collection}

The Semane oceanographic experiments were conducted by SHOM in June 1995 and September 1997, in the northern half of the Gulf of Cadiz and southwest of Portugal. The experimental array is presented in figure 1. Both experiments comprised two legs at a fortnight interval; during each leg, zonal and meridional sections were performed across the Mediter- 
ranean water undercurrents with $\mathrm{XBT}$ and $\mathrm{XCTD}^{1}$ casts (210 during Semane 95, 130 during Semane 97), and CTD $/$ LADCP $^{2}$ stations (61 during Semane 95 and 52 during Semane 97). The horizontal resolution of the hydrological sections was smaller than $10 \mathrm{~km}$ in the undercurrents, and up to $25 \mathrm{~km}$ offshore. Some sections, near Portimão canyon and south of Cape Saint Vincent, were achieved in both experiments.

Deep-drogued Surdrift buoys were also deployed in both experiments to follow the undercurrents and their mesoscale fluctuations in near real time. Surdrifts are surface buoys localized via Argos (here for a 3-month period). These buoys are linked to $10 \mathrm{~m}$ high holeysock drogues, by a kevlar cable of $2.1 \mathrm{~mm}$ diameter. These drogues were immersed at depths between 700 and $1300 \mathrm{~m}$. Rafos floats were deployed only in 1997. They reached equilibrium depths between 950 and $1400 \mathrm{~m}$. They were located every eight hours by acoustic triangulation, using four moored sound sources southwest of Portugal, and four others northwest of Portugal.

\subsection{Data processing}

Hydrological profiles were first calibrated on in situ measurements (surface temperature and salinity analysis of water samples). Then a median filter and an individual inspection were applied to eliminate spurious points on each profile. A Newtonian binomial smoothing was used, and the number of points was finally reduced to 10 or $20 \%$ of the initial value. This procedure always ensured that each profile could be reconstructed by linear interpolation from the reduced dataset with a minimal error.

By performing a water mass analysis, we determined the $(\theta, S)$ relation in the upper and lower cores of Mediterranean Water, and out of the Mediterranean Water, both south and west of Portugal. This relation was then used to obtain salinity values from temperature profiles (XBT casts, Käse et al., 1996). This method was validated on CTD stations where precise values of both $\theta$ and $S$ were available.

Geostrophic velocities were then calculated by verti-

\footnotetext{
${ }^{1}$ eXpendable BathyThermographs, eXpendable Conductivity Temperature Depth probes.

${ }^{2}$ Conductivity Temperature Depths probes, Lowered Acoustic Doppler Current Profiler.
}

cally integrating the thermal wind relation $\left(\partial_{z} u=\right.$ $\left.\mathrm{g} \partial_{\mathrm{y}} \rho /(\rho \mathrm{f}), \partial_{\mathrm{z}} \mathrm{v}=\mathrm{g} \partial_{\mathrm{x}} \rho /(\rho \mathrm{f})\right)$, where $(\mathrm{u}, \mathrm{v})$ is horizontal velocity, $g$ is gravity, $f$ is the Coriolis parameter, $\rho$ is the local density. A level of no motion was chosen at the salinity minimum between the Central Water and the Mediterranean Water (near $500 \mathrm{~m}$, see also Ambar and Howe, 1979).

LADCP data was processed by the sequence of algorithms designed by E. Firing. The method consists in the vertical integration of vertical shears of horizontal velocity to restore absolute horizontal velocities, with a reference at the sea surface. To eliminate the bias between the downward and upward profiles, corrections were applied to the deepest point of each station to match both profiles.

From velocity and density data, anomalies of Ertel potential vorticity were computed as $\delta \mathrm{Q}=-(\zeta+$ f) $\left(\partial_{z} \rho / \rho\right)+f \partial_{z} \rho_{0} / \rho_{0}$ where $\zeta=\partial_{x} v-\partial_{y} u$ is the relative vorticity and $\rho_{0}$ is the reference density. Near Portimão canyon, the reference potential vorticity $f \partial_{z} \rho_{0} / \rho_{0}$ was computed at a point south of all meridional sections, out of the Mediterranean Water cores.

Surdrift trajectories were low-pass filtered at three days and resampled every four hours. A test on their relative acceleration was also performed to determine the possible loss of the drogue (resulting from human action, fishbites or bad weather conditions). Despite their $1000 \mathrm{~m}$ long cable, surdrift velocities were surprisingly close to velocities measured by LADCP (the errors lying within $25 \%$ ) (Chérubin et al., 1997).

Finally, Rafos float positions were determined using the best two acoustic signals for each eight hour cycle. Spurious positions were eliminated whenever unrealistic accelerations were obtained. Linear interpolation between validated positions was used in such cases.

\section{RESULTS}

\subsection{Mesoscale structure of the Mediterranean Water undercurrents south and west of Portugal; characteristics of unstable events}

This section presents unstable events of the Mediterranean Water undercurrents associated with local topographic influence.

Figure 2 displays a quasi-synoptic view of the salinity distribution at $1300 \mathrm{~m}$ in the Gulf of Cadiz and 


\section{Semane 95 - Salinity $1300 \mathrm{~m}$}

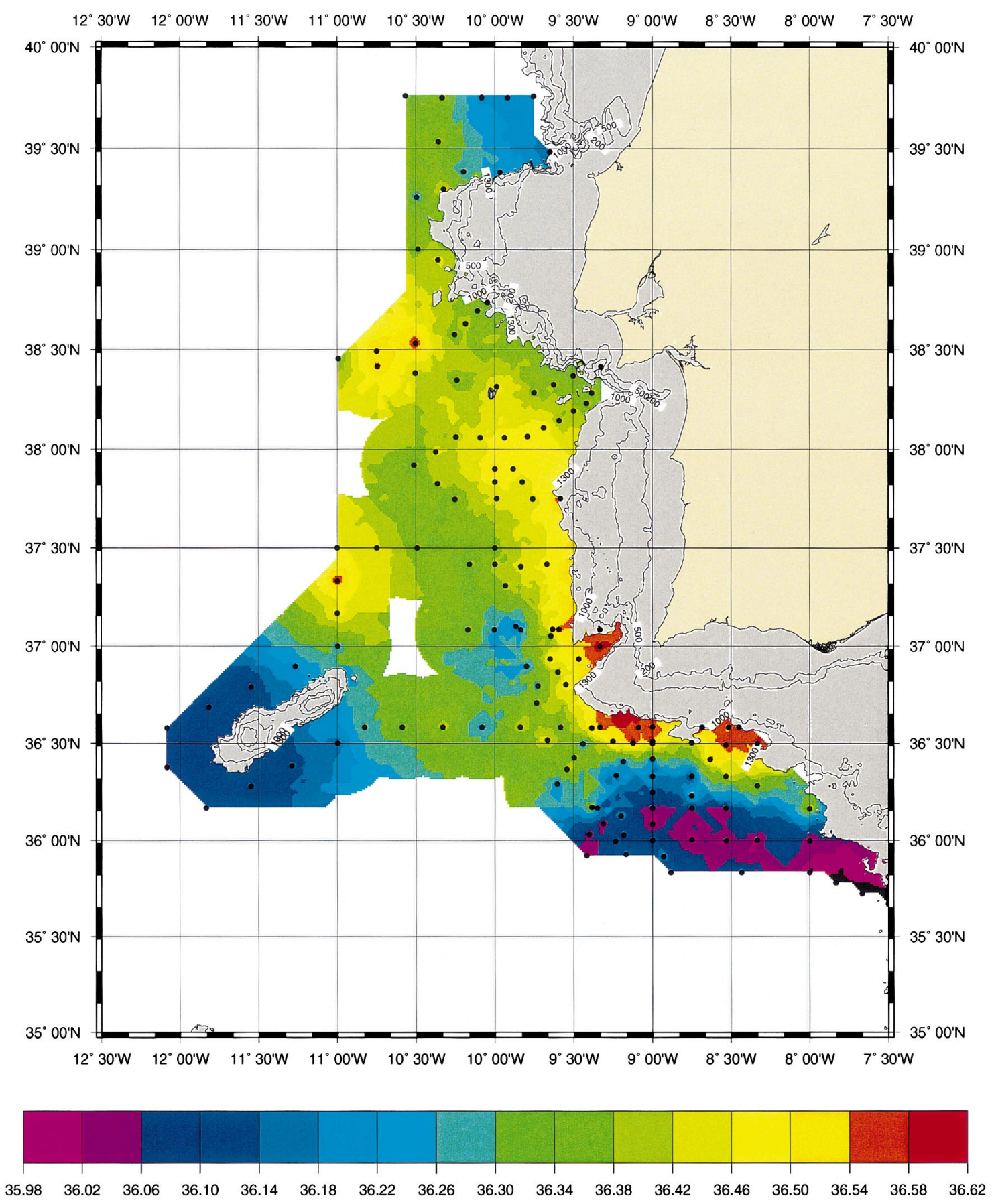

Figure 2. Horizontal maps of salinity at $1300 \mathrm{~m}$ in the Gulf of Cadiz and southwest of Portugal during Semane 95. 
southwest of Portugal, obtained with Semane 95 data (Semane 97 data are very similar).

South of Portugal, the lower core of Mediterranean Water fills Portimão canyon (at $36^{\circ} 40^{\prime} \mathrm{N}, 8^{\circ} 32^{\prime} \mathrm{W}$ ), and widens again near $36^{\circ} 40^{\prime} \mathrm{N}, 9^{\circ} 15^{\prime} \mathrm{W}$. A zoom of Semane 95 data in this region (not shown) evidences a small lens and a filament of Mediterranean Water near $36^{\circ} 15^{\prime} \mathrm{N}, 9^{\circ} 25^{\prime} \mathrm{W}$; the Semane 97 data also show a salty fragment near that location. A strong haline anomaly is also noticeable in Saint Vincent Canyon (near $37^{\circ} \mathrm{N}, 9^{\circ} 20^{\prime} \mathrm{W}$ ).

South of Portimão Canyon (near $36^{\circ} 10^{\prime} \mathrm{N}, 8^{\circ} 32^{\prime} \mathrm{W}$ ), the lower core of Mediterranean Water is separated from the surrounding Atlantic water by a sharp haline front; similarly, the upper core at $800 \mathrm{~m}$ is bounded by a sharp thermal front (not shown). Further west, this strong thermohaline gradient diminishes as the current rotates around Cape Saint Vincent. Two reasons can account for this decrease: first, the centrifugal force associated with rotation expels the salty slope waters radially, and secondly, meddy formation at Cape Saint Vincent is a nonlinear process which enhances mixing and weakens thermohaline gradients.

Southwest and west of Portugal, the Semane 95 data exhibit several interesting features of the lower core: first, it is deviated northwestward between $37^{\circ} 30^{\prime} \mathrm{N}$ and $38^{\circ} 20^{\prime} \mathrm{N}, 9^{\circ} 30^{\prime} \mathrm{W}$ and $10^{\circ} \mathrm{W}$; this deviation can result from the extruding isobaths (the topographic spur) near $9^{\circ} 30^{\prime} \mathrm{W}, 37^{\circ} 40^{\prime} \mathrm{N}$. In fact, this deviation is not systematic; Lagrangian data (see hereafter) show that the lower core can also follow the $1500 \mathrm{~m}$ isobath and be later influenced by the Setubal and Lisbon canyons. The Semane 95 temperature map at $800 \mathrm{~m}$ (not shown) indicates that the upper core is not deviated by the spur and spreads widely over the Setubal and Lisbon canyons.

Farther offshore, two large salty patches are detached from the lower core. One is located near $38^{\circ} 30^{\prime} \mathrm{N}, 10^{\circ}$ $45^{\prime} \mathrm{W}$ over a bathymetric trough; its precise shape cannot be determined with the available data. Another salinity maximum is found along $11^{\circ} \mathrm{W}$, between $37^{\circ}$ $10^{\prime} \mathrm{N}$ and $37^{\circ} 40^{\prime} \mathrm{N}$. The following section will evidence that it is a meddy, most likely originating from Cape Saint Vincent.

More information on the Mediterranean undercurrents and eddies can be gained by analyzing the trajectories of Lagrangian floats. First, deep-drogued Surdrift buoys of Semane 95, trapped in the undercurrents, follow quasi-laminar trajectories around Cape Saint Vincent (figure 3a). These trajectories display no repeated loops near the Cape, nor westward propagation from the Cape, and thus show an absence of meddy formation at the time. Secondly, the buoys are not deflected northwestward by topographic spur at $9^{\circ}$ $30^{\prime} \mathrm{W}, 37^{\circ} 40^{\prime} \mathrm{N}$, except buoy 23446 drogued at $1100 \mathrm{~m}$. Still, anticyclonic loops in buoy 23451 trajectory (at $750 \mathrm{~m}$ ) begin near this spur; these loops are small (20 km in diameter). Thirdly, similarly small loops of buoy 23450 (at $1000 \mathrm{~m}$ ) begin near the Setubal and Lisbon canyons. These loops amplify downstream to finally reach $80 \mathrm{~km}$ in diameter (the typical size of a meddy) southwest of Estramadura Promontory, where the large salty patch is observed. We also notice that the cyclonic loops of buoy 23448 (at $1300 \mathrm{~m}$ ) are correlated with the anticyclonic motion of buoy 23450 (at $1000 \mathrm{~m}$ ). Therefore, the meddy thus formed has (at least) a dipolar structure.

Similar information is obtained when analyzing surdrift trajectories of Semane 97 (figure 3b): large anticyclonic loops correspond to meddy formation west of the Estramadura Promontory. These buoys are then expelled from the eddies, and follow a westward trajectory characteristic of the turbulent salt flux in this region. Buoys launched between $37^{\circ} \mathrm{N}$ and $38^{\circ} \mathrm{N}$ drift southwestward, again in the direction of the eddy flux. Rafos trajectories of Semane 97 also indicate the influence of the topographic spur at $9^{\circ} 30^{\prime} \mathrm{W}, 37^{\circ} 40^{\prime}$ $\mathrm{N}$ on the lower current of Mediterranean Water (not shown).

Finally, figure 4 gives the location of the temperature and salinity maxima in the undercurrents (respectively around 800 and $1200 \mathrm{~m}$ ) calculated from the Semane 95 dataset. The lower core most often lies offshore of the upper core. The undercurrents align vertically only near sites where their instability has been observed historically:

- both cores move offshore under the influence of centrifugal force where topography is extruding (Cape Saint Vincent, the spur at $9^{\circ} 30^{\prime} \mathrm{W}, 37^{\circ} 40^{\prime}$ $\mathrm{N}$, the western tip of the Estramadura Promontory); in fact, the upper core is more displaced than the lower core since shallow topographic anomalies are more marked than deep ones. 
(a) Buoy $17578(700 \mathrm{~m})$

Buoy $23441(1000 \mathrm{~m})$

Buoy 23442 (1150m)

Buoy 23444 (800m)

Buoy $23445(1200 \mathrm{~m})$

Buoy $23446(1100 \mathrm{~m})$

Buoy $23447(800 \mathrm{~m})$

Buoy $23448(1300 \mathrm{~m})$

Buoy $23450(1000 \mathrm{~m})$

Buoy $23451(750 \mathrm{~m})$

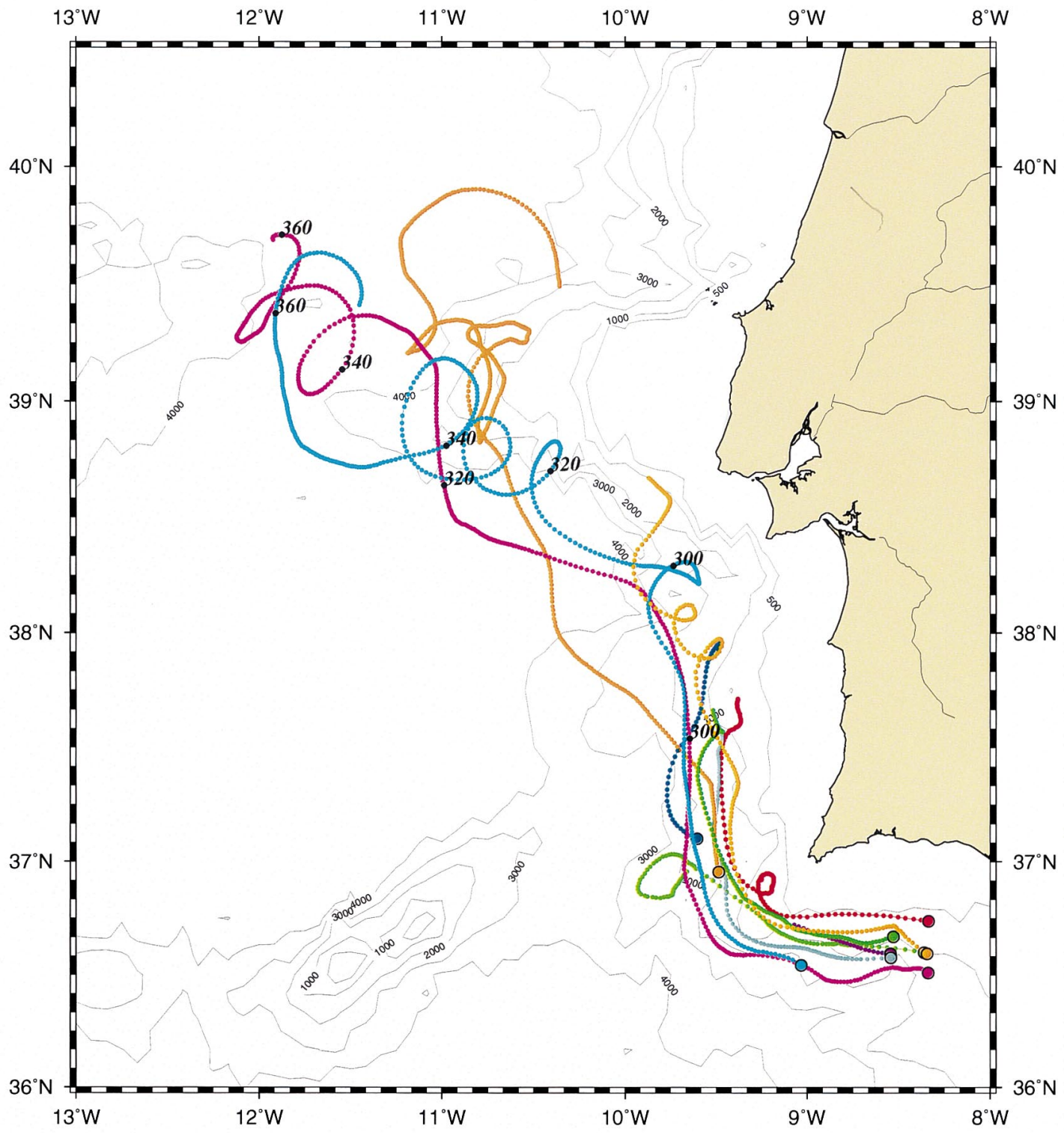

Figure 3. (a) trajectories of deep-drogued Surdrift buoys during Semane 95 (figures between parentheses indicate the depth of the drogue); the dots indicate the position of the float at a given day of the year; (b) same as (a) during Semane 97. 
(b) Buoy $16835(1300 \mathrm{~m})$

Buoy 16844 (900m)

Buoy $16846(1100 \mathrm{~m})$

Buoy 16848 (1200m)

Buoy $16849(1300 \mathrm{~m})$
Buoy $23449(1000 \mathrm{~m})$

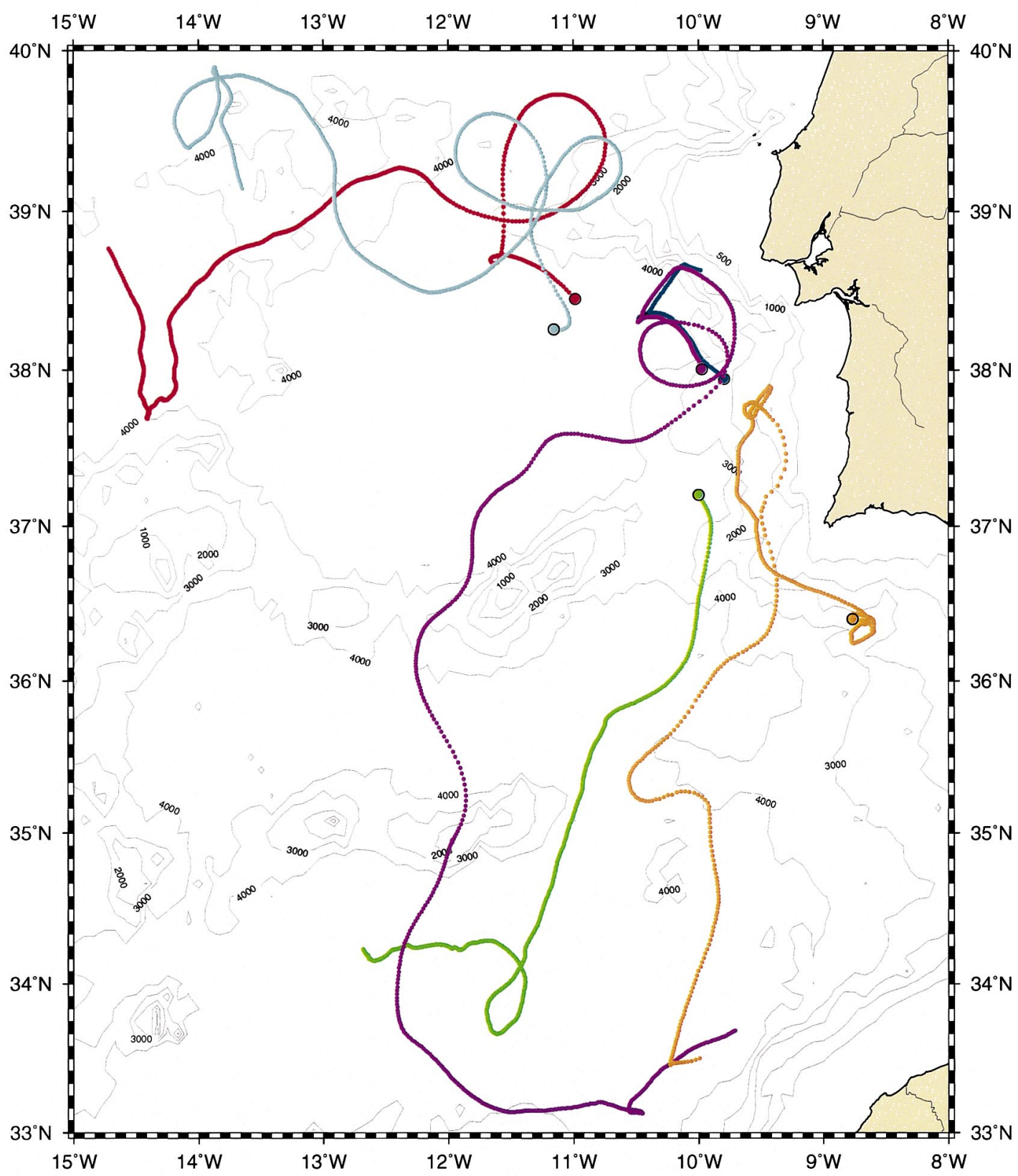

Fig. 3. (Continued) 


\section{Max T (upper MW core) and S (lower core) during Semane95}

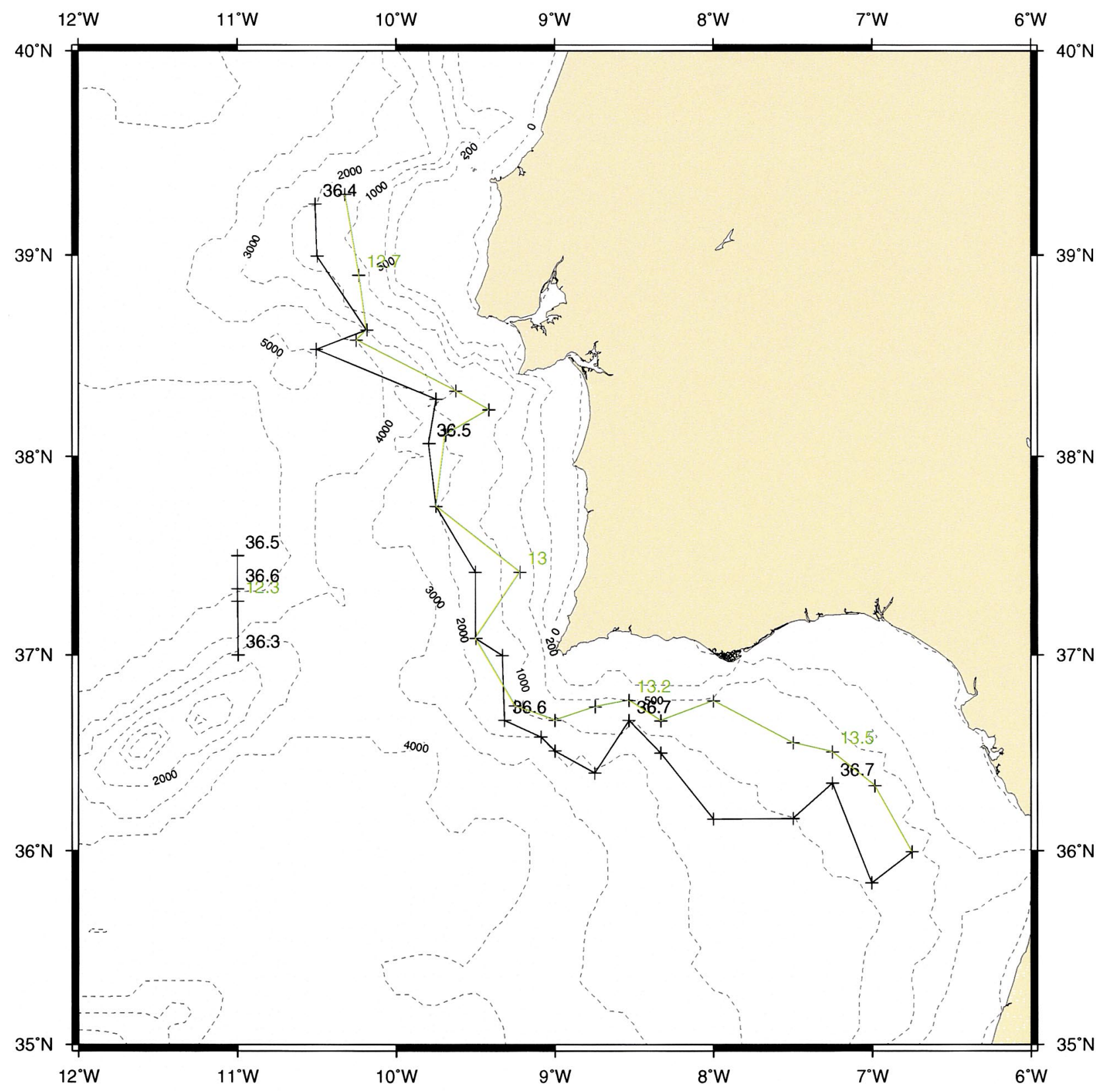

Figure 4. Location of the temperature and salinity maxima respectively at 800 and at $1200 \mathrm{~m}$ (characterizing the upper and lower cores), along the Iberian shelf, during Semane 95. The meddy west of Cape Saint Vincent is also indicated.

- the lower core moves inshore where topography is narrowing; this is most noticeable over Porti- mão canyon. This path is due to the topographic steering of the current by the canyon. 
This vertical alignment of the two undercurrents amplifies baroclinic instability. Indeed, these currents are bounded by sharp potential vorticity gradients (see section 3.3). Theoretical studies of the baroclinic instability of potential vorticity fronts (e.g. Hoskins et al., 1991) prove that vertically aligned fronts yield maximum resonance of phase-locked Rossby waves, hence maximum growth of perturbations.

This theory is all the more relevant to the Mediterranean Water undercurrents as their external boundary is indeed a front. Around Cape Saint Vincent, where radial thermohaline gradients are more diffuse, baroclinic instability may be weakened compared with Portimão canyon where the meridional thermohaline gradient is very strong.

In summary, instability of the Mediterranean Water undercurrents southwest of Portugal occurs preferentially near topographic anomalies (capes, canyons and spurs). Near canyons in particular, the vertical alignment of the undercurrents can be favorable to their baroclinic instability.

\subsection{Detailed analysis of currents and eddies near Portimão canyon and Cape Saint Vincent}

This section presents high-resolution hydrological sections of the Mediterranean Water cores near Portimão canyon, to evidence the dynamical influence of this canyon on these undercurrents.

Figure $5 a, b$ are temperature and salinity sections across the Mediterranean undercurrents near Portimão canyon for both Semane experiments: from left to right, the plots correspond to the eastern flank, central axis and western flank of the canyon. Upstream of the canyon (at $8^{\circ} 20^{\prime} \mathrm{W}$ ), the lower core of Mediterranean Water is fairly wide $(40$ to $50 \mathrm{~km})$ and is composed of two parts separated by a topographic peak near $36^{\circ} 30^{\prime} \mathrm{N}$. In 1997, the southern branch of the lower core is more spread out than in 1995. Inside the canyon (at $8^{\circ} 32^{\prime} \mathrm{W}$ ), the undercurrents remain wide and tend to align vertically. In 1997, a small vortex forms in the canyon, near $36^{\circ} 20^{\prime} \mathrm{N}$; it has a $40 \mathrm{~km}$ diameter. This eddy ressembles that observed farther west during the Gulf of Cadiz experiment (Prater and Sanford, 1994). Downstream of the canyon (at $8^{\circ} 45^{\prime} \mathrm{W}$ ), the undercurrents narrow down along the slope, while a southern branch of the lower core is visible offshore, near $36^{\circ} 20^{\prime} \mathrm{N}$. A strong decrease in salinity is noted from upstream to downstream: this decrease can be associated with strong mixing or with unstable events.

LADCP measurements of Mediterranean Water currents yield velocity maxima up to $50 \mathrm{~cm} \mathrm{~s}^{-1}$ upstream of the canyon (near $900 \mathrm{~m}$ depth), slowing down to $30 \mathrm{~cm} \mathrm{~s}^{-1}$ in the canyon (for the southern branch) and accelerating downstream (back to $40 \mathrm{~cm} \mathrm{~s}^{-1}$ ). In the 1997 data, anticyclonic velocities reach $10 \mathrm{~cm} \mathrm{~s}^{-1}$ on the northern side of the eddy in the canyon (near $36^{\circ}$ $25^{\prime} \mathrm{N}, 8^{\circ} 32^{\prime} \mathrm{W}$, at $1300 \mathrm{~m}$ depth).

Figure $5 c$ is a zonal section of thermohaline properties and velocity (issued from LADCP measurements) across the head of the Portimão canyon (along $36^{\circ} 35^{\prime}$ $\mathrm{N})$. The upper core of Mediterranean Water and at least part of the lower one move shoreward on the eastern flank of the canyon, thus bringing warm and salty water towards the head of the canyon. The velocity structure is baroclinic with the $800 \mathrm{~m}$ maximum west of the $1200 \mathrm{~m}$ one. On the western flank of the canyon, the southward flow is more barotropic. The zonal velocity is westward at all depths.

This splitting of the lower undercurrent into an inshore current, which follows isobaths, and an offshore current which flows quasi-zonally in the canyon is evidenced on the horizontal maps of velocity, for both Semane 95 and 97 experiments (figure 5d,e). In 1995, the flow at 800 and $1100 \mathrm{~m}$ follows the bathymetry north of $36^{\circ} 30^{\prime} \mathrm{N}$, in the Portimão canyon. In 1997, the LADCP data is less dense, but similar along-isobath flow is observed near the head of the canyon, and an anticyclonic eddy lies near its mouth. The velocity vectors at $1100 \mathrm{~m}$ confirm that part of the lower undercurrent follows the continental slope while a second branch is present offshore, which joins the inshore branch west of Portimão canyon.

Farther west (along $11^{\circ} \mathrm{W}$, from $37^{\circ} \mathrm{N}$ to $37^{\circ} 30^{\prime} \mathrm{N}$ ), a short XBT-XCTD section evidences the meddy mentioned in the previous section: it is a large lens of (relatively) warm and salty water, intensified between 750 and $1500 \mathrm{~m}$ (figure $5 f$ ). Its maximum temperature is weak (between $12.3^{\circ} \mathrm{C}$ and $12.8^{\circ} \mathrm{C}$ ), but its salinity is large (36.6). From the southern half of the section, better sampled, we can estimate that this meddy is approximately $80 \mathrm{~km}$ wide, since the section may not cross this meddy through its center. Therefore, this 

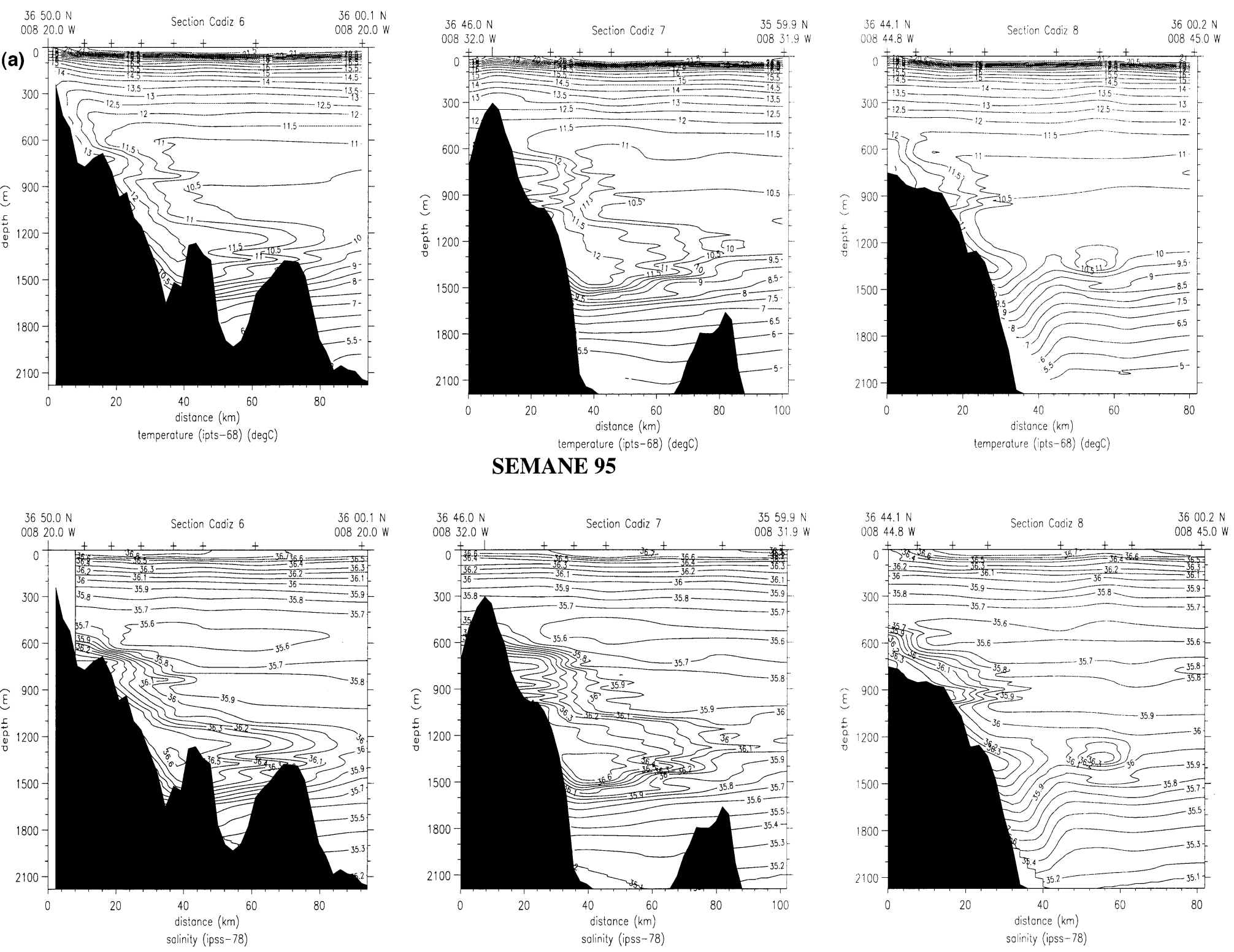

Figure 5. (a, b) Temperature and salinity cross-sections (latitude-depth plane) of the Mediterranean undercurrents, upstream, within and downstream of Portimão canyon, during Semane 95 and Semane 97; (c) temperature, salinity and velocity cross-sections along $36^{\circ} 35^{\prime} \mathrm{N}$ between $8^{\circ} 20^{\prime} \mathrm{W}$ and $8^{\circ} 45^{\prime} \mathrm{W}$; (d) horizontal maps of velocity at 800 and $1100 \mathrm{~m}$ in the Portimão canyon and south of Cape Saint Vincent during Semane 95; (e) same as (d) during Semane 97; (f) temperature and salinity cross-sections along $11^{\circ} \mathrm{W}$ between $37^{\circ} \mathrm{N}$ and $37^{\circ} 30^{\prime} \mathrm{N}$, showing a meddy west of Cape Saint Vincent during Semane 95. 

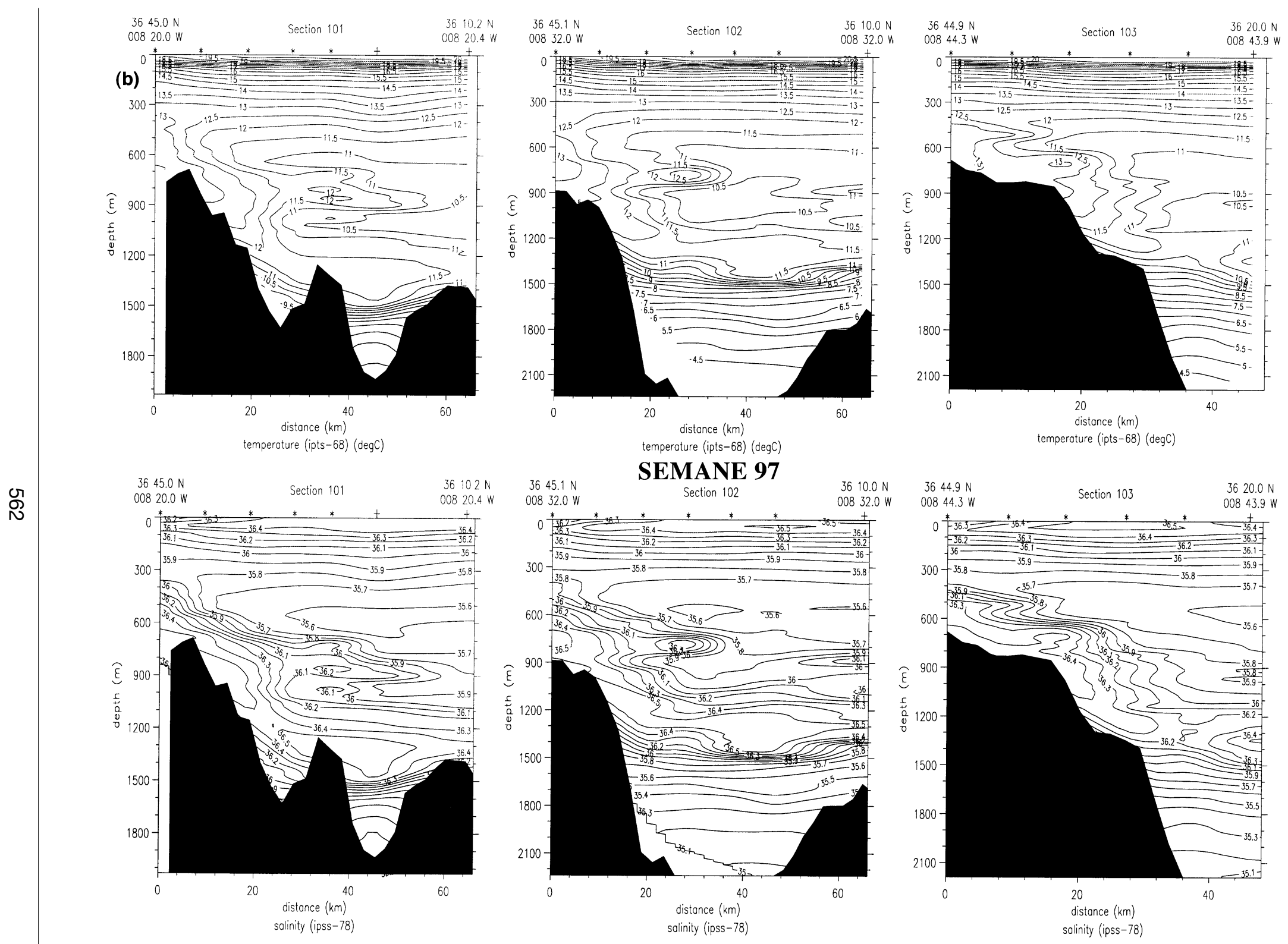

Fig. 5. (Continued) 

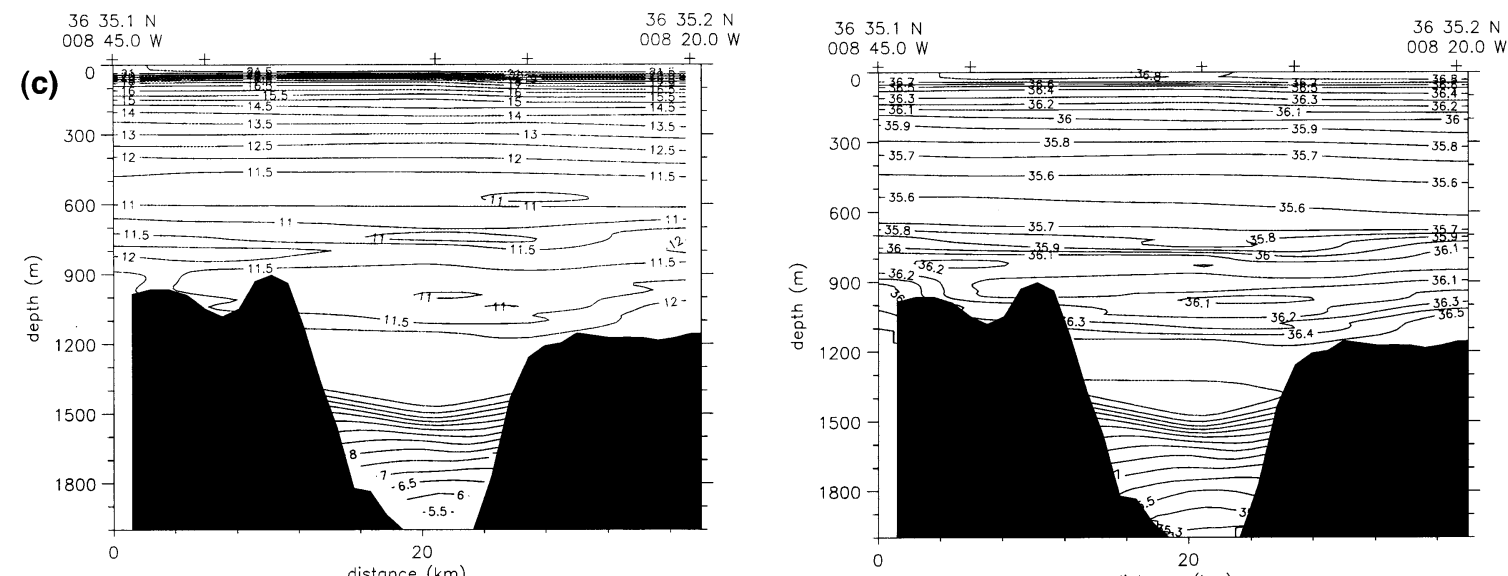

temperoture (ipts-68) (deqC)

ity (ipss-78)

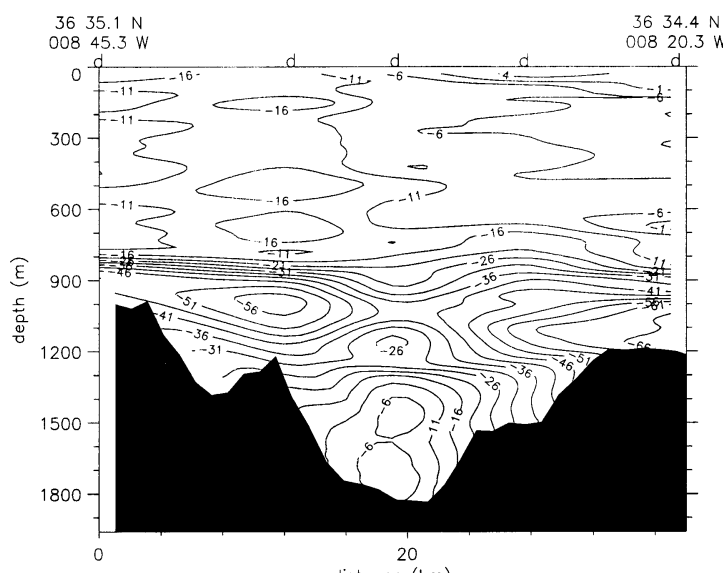

distance $(\mathrm{km})$
$\mathrm{u}(\mathrm{cm} . \mathrm{s}-1)$

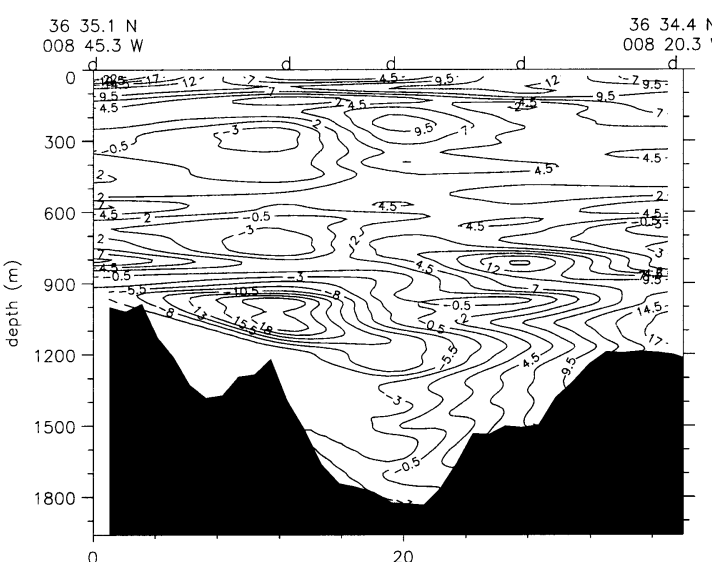

20
distance $(\mathrm{km})$

Fig. 5. (Continued) 


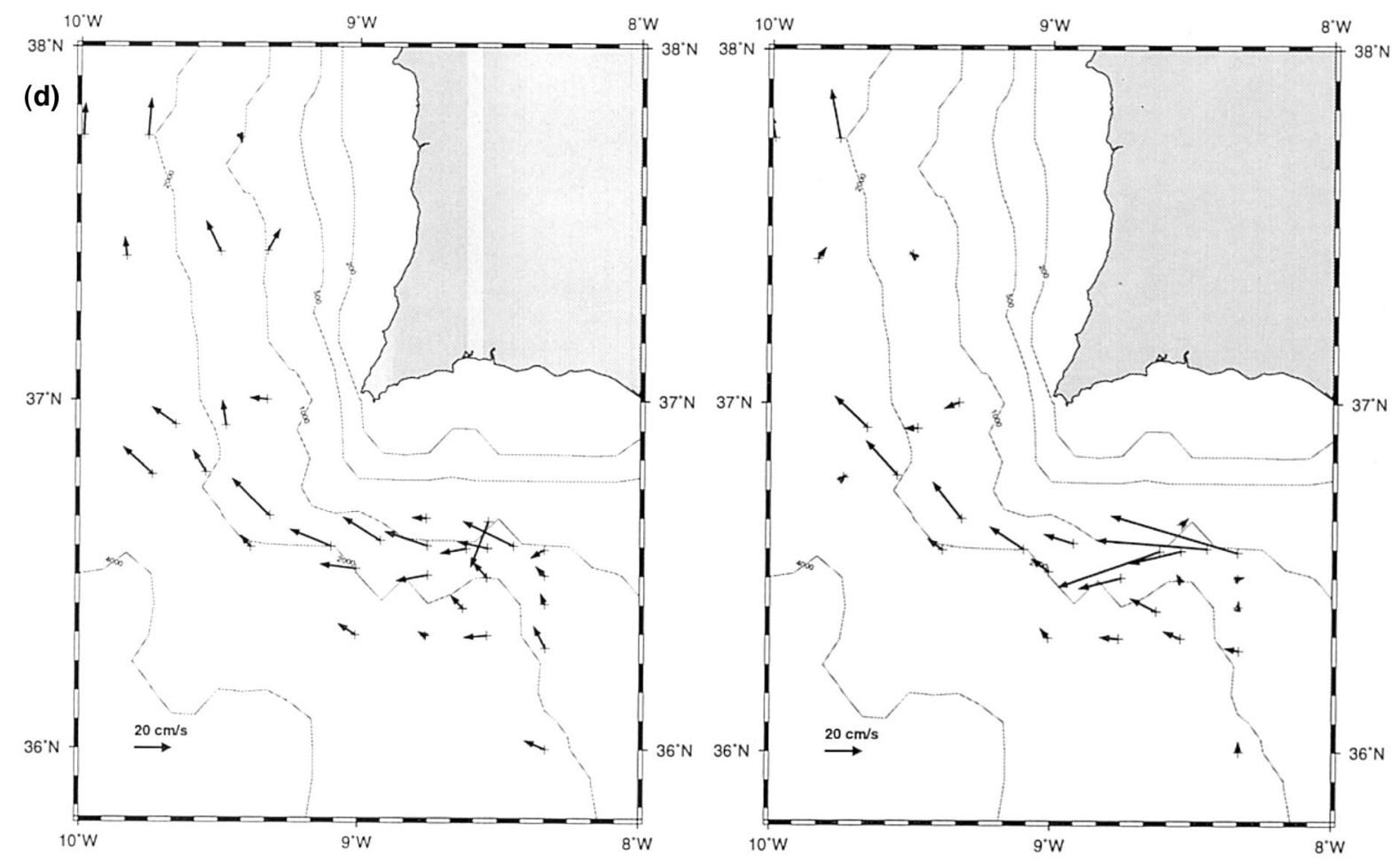

Fig. 5. (Continued) 


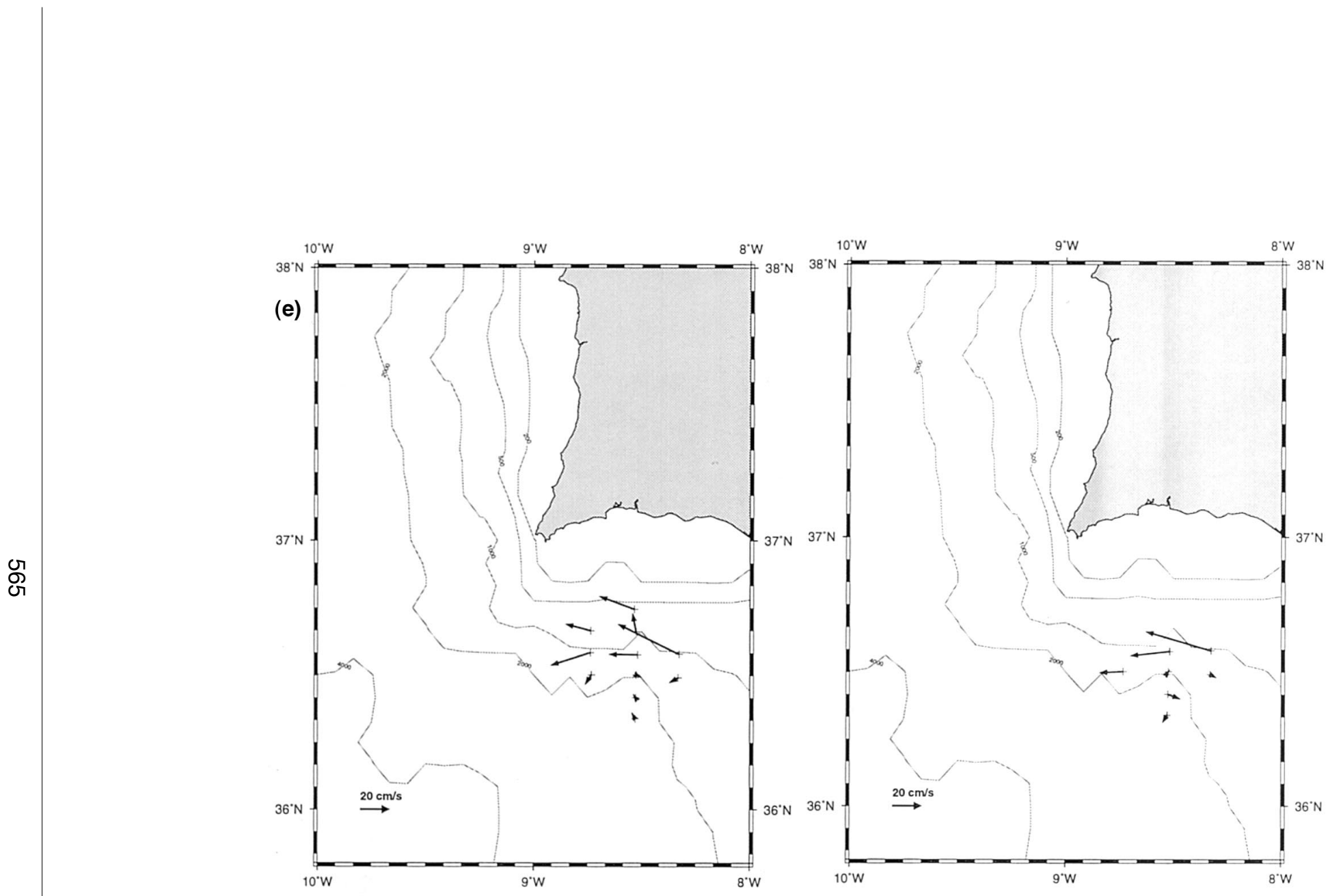

Fig. 5. (Continued)

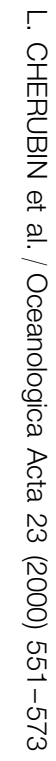



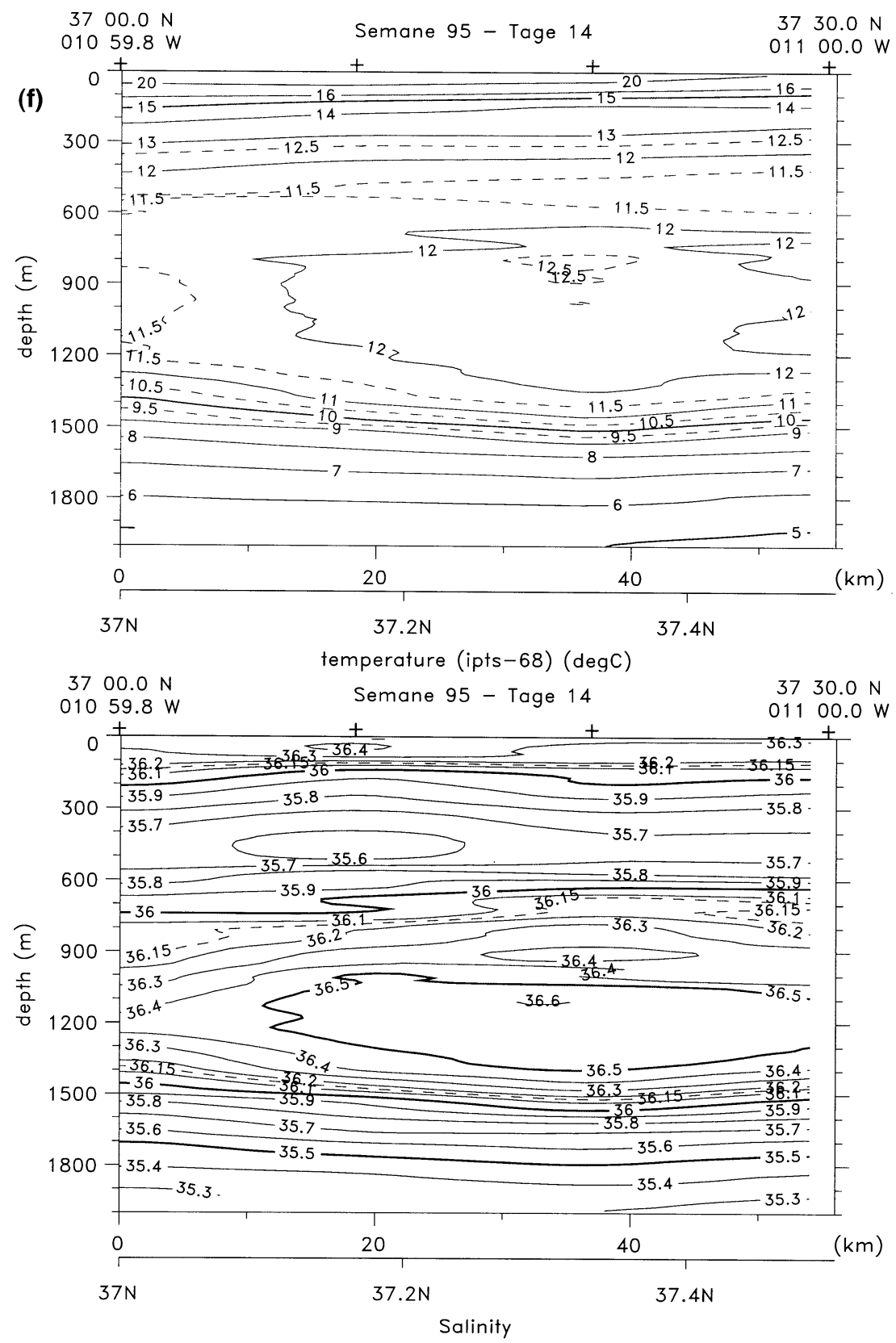

Fig. 5. (Continued) 
meddy is at least twice as large as the eddy formed in the Portimão canyon. This meddy salinity and position designate Cape Saint Vincent as a likely generation site (see figure 4). Indeed, a westward drift of this meddy after its formation is a reasonable assumption considering known meddy trajectories from Cape Saint Vincent (Bower et al., 1995, 1997).

Assuming a level of no motion at $2000 \mathrm{~m}$, geostrophic velocity calculations yield a maximum azimuthal velocity slightly above $15 \mathrm{~cm} \mathrm{~s}^{-1}$ for this meddy; this maximum lies $10 \mathrm{~km}$ away from the meddy axis. The cyclostrophic correction is approximately $2.6 \mathrm{~cm} \mathrm{~s}^{-1}$; thus the total velocity is at most $\mathrm{V}_{\theta}=18 \mathrm{~cm} \mathrm{~s}^{-1}$. Though this value may be approximate because of the coarse sampling of measurements, it is close to maximum azimuthal velocities already measured in meddies (Tychensky and Carton, 1998; Paillet et al., 1999).

In summary, hydrological and LADCP data indicate that the lower core of Mediterranean Water is composed of two branches over the Portimão canyon; the northern one follows the isobaths while the southern one crosses the canyon, sometimes creating a small eddy. West of Cape Saint Vincent, a large meddy is observed, which can reasonably have formed at the cape. Both eddies are baroclinic: their homogeneous anticyclonic core is thermocline-intensified, squeezing isotherms and isohalines above and below.

\subsection{Potential vorticity sections near Portimão canyon and nature of the instability}

This section analyzes sections of potential vorticity anomaly across the undercurrents over the Portimão canyon, to characterize the nature of their instability. The Semane 95 data are shown since the Semane 97 cross-sections had a lower spatial resolution.

Figure 6 displays the sections upstream, within and downstream of the canyon.

Since potential vorticity is presented in isopycnic coordinates (where topography is only sketched), a vertical cross-section of $\sigma_{1}$ density is also provided.

The potential vorticity section upstream of the Portimão canyon (called "section 1") exhibits a baroclinic structure, with five levels of alternate-sign anomalies:
- strong positive anomaly is found near the shelf at $\sigma_{1}=31.8$. This anomaly is due to the squeezing of isopycnal surface above the Mediterranean Water cores (near $700 \mathrm{~m}$ depth);

- between $\sigma_{1}=31.9$ and $\sigma_{1}=32.05$ (800 and 1000 $\mathrm{m}$ depths), a negative anomaly corresponds to the homogeneous upper core;

- a second positive anomaly is present between $\sigma_{1}=32.05$ and $\sigma_{1}=32.15(1000-1100 \mathrm{~m})$; this layer is located between the two Mediterranean Water cores, where isopycnals are also squeezed;

- the lower core is found between $\sigma_{1}=32.15$ and $\sigma_{1}=32.3(1100-1500 \mathrm{~m})$, again with negative anomaly due to vortex stretching;

- finally, positive potential vorticity anomaly is found below the lower core $\left(\sigma_{1}>32.3\right)$, where isopycnals are squeezed.

This picture can be simplified by gathering these anomalies in two groups, associated with the two cores of Mediterranean Water, the upper one between $\sigma_{1}=31.8$ and $\sigma_{1}=32.1$, the lower one between $\sigma_{1}=32.1$ and $\sigma_{1}=32.3$ (see the density plot below the vorticity plot). If relative vorticity is not included when calculating potential vorticity, a similar vertical structure, though weaker, is still obtained. Note that the horizontal/vertical reversals of meridional gradients of potential vorticity observed here are a necessary condition for barotropic/baroclinic instabilities (Rayleigh-Kuo and Charney-Stern criteria).

Within the canyon ("section 3"), the structure is globally similar, but the following changes are noted:

- the positive anomaly at $\sigma_{1}=32.1$ has intensified; its maximum is located slightly offshore $(15 \mathrm{~km}$ away from the slope); it corresponds to the offshore edge of the lower core;

- the deep $\left(\sigma_{1}=32.4\right)$ positive anomaly has increased. Isopycnals are squeezed as the lower core falls into the canyon.

Two essential effects with regard to instability are thus: (1) stronger horizontal gradients of potential vorticity anomalies reinforcing the possibility of barotropic instability; (2) a stronger vertical gradient of potential vorticity anomaly below the lower core, intensifying baroclinic instability.

Finally, when the current exits the canyon ("section 5 "), the potential vorticity anomalies weaken and 
squeeze shoreward. Their vertical structure is comparable with that upstream of the canyon.

In summary, the potential vorticity structure of the Mediterranean Water cores allows baroclinic instability. The canyon reinforces horizontal and vertical gradients of potential vorticity, thereby favoring barotropic and baroclinic instabilities.

\subsection{Steady-state model of a coastal jet over a canyon}

This section provides a simple theoretical model which describes the effect of a canyon on a coastal current, by using invariant properties of the flow in a steady state.
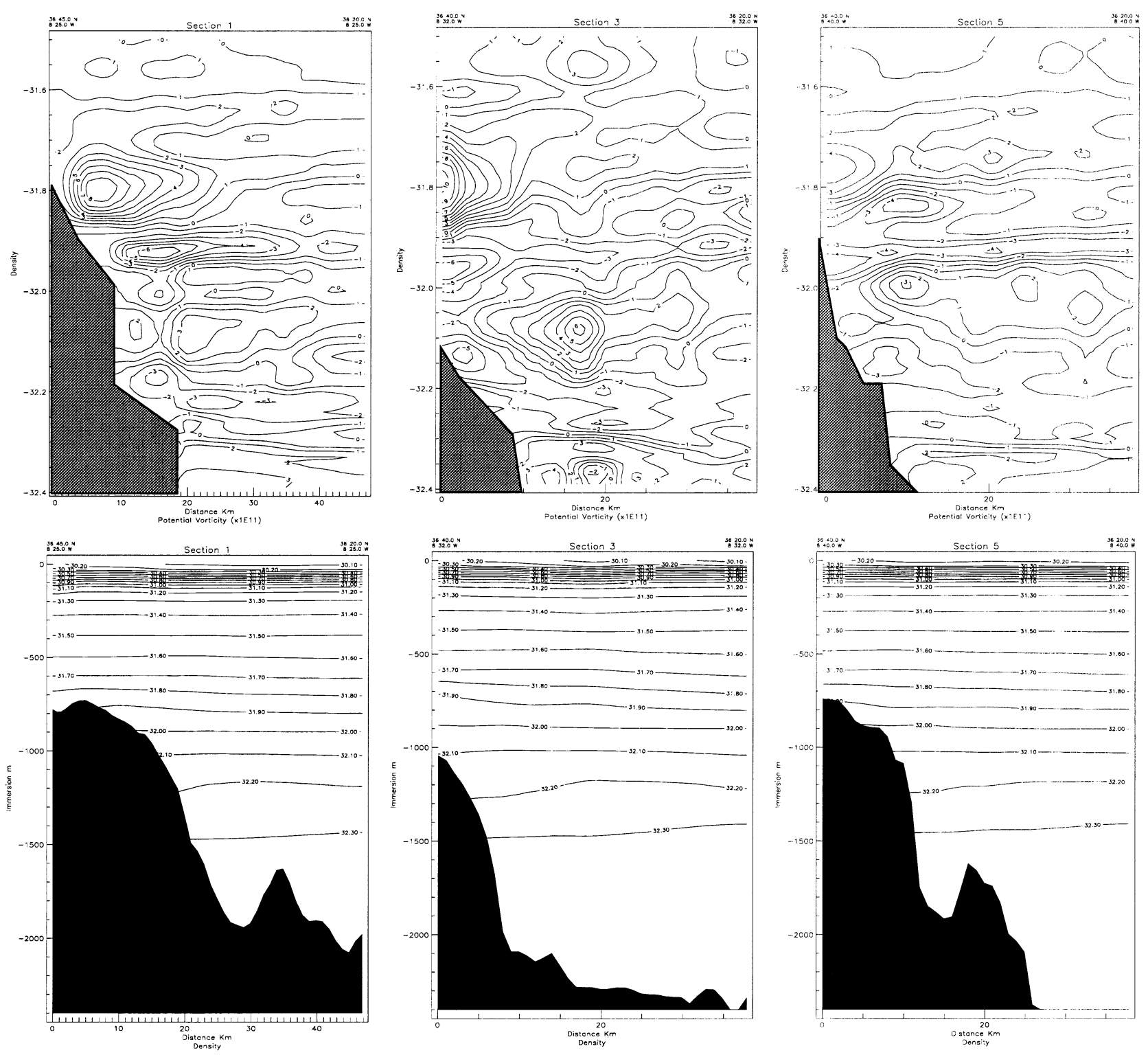

Figure 6. Meridional cross-sections of Ertel potential vorticity anomaly (top) and their respective density section (bottom), upstream, within and downstream of Portimão canyon, during Semane 95. On potential vorticity maps, bottom topography is only sketched and shaded in grey. 


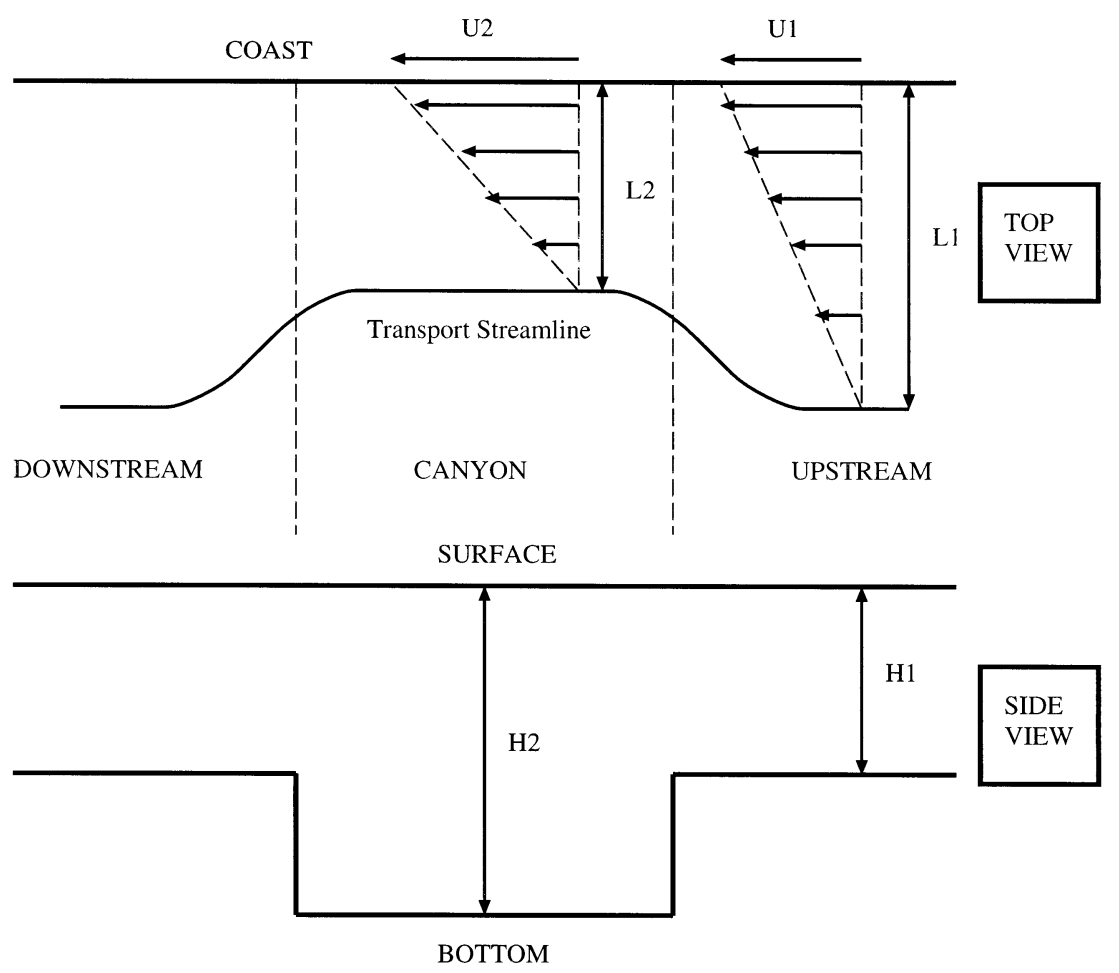

Figure 7. Schematic diagram of a coastal jet over a canyon in the steady state model.

Three-dimensional models are often used to reproduce both the horizontal and vertical flows over a canyon. Here we are only interested in the horizontal structure of the flow, and we use a shallow-water model. This model is appropriate here since the flow has a weak aspect ratio and also satisfies hydrostatic balance and Boussinesq approximation. We only model the lower core, assuming moreover that it is homogeneous and bounded above and below by rigid surfaces.

For unforced and non dissipative flows, the shallowwater equations are written:

$\partial_{t} u+u \partial_{x} u+v \partial_{y} u-f_{0} v=\frac{-1}{\rho} \partial x p$

$\partial_{t} v+u \partial_{x} v+v \partial_{y} v+f_{0} u=\frac{-1}{\rho} \partial y p$

$\partial_{t} h+u \partial_{x} h+v \partial_{y} h+h\left(\partial_{x} u+\partial_{y} v\right)=0$

with the f-plane approximation. Taking the curl of equations (1) and (2), and substituting the horizontal velocity divergence in equation (3), yields the conservation of potential vorticity: $\left(\partial_{t}+u \partial_{x}+v \partial_{y}\right) q=0, \quad q=\frac{\zeta+f_{0}}{h}$

Using the stationarity hypothesis, equation (3) proves the existence of a transport streamfunction from which the mass flux derives:

$\partial_{x}(h u)+\partial_{y}(h v)=0 \Rightarrow h \vec{u}=\vec{k} \wedge \vec{\nabla} \psi$

Multiplying the stationary version of equation (4) by $h$ yields:

$J(\phi, q)=0$

where $\mathbf{J}$ is the Jacobian operator. Therefore, potential vorticity is constant along transport streamlines.

Figure 7 displays the top and side views of a sheared coastal jet, with maximum velocity $\mathrm{U}_{1}<0$ and width $\mathrm{L}_{1}$; hereafter we set $\mathrm{V}_{1}=-\mathrm{U}_{1}>0$. This current flows over a flat bottom (upstream of the canyon) in an ocean of depth $\mathrm{H}_{1}$. It encounters a perpendicular canyon; this canyon is a trench where the local ocean depth is $\mathrm{H}_{2}$. We assume that the flow reaches a steady state both in the canyon, upstream and downstream, and that the velocity remains zonal. For a positive shear of the flow, the relative vorticity is $\zeta_{1}=\mathrm{V}_{1} / \mathrm{L}_{1}$. 
Potential vorticity is piecewise-constant, and the transport streamline bounding the current is also a potential vorticity front.

Conservation of potential vorticity and of mass flux between upstream and canyon positions is written:

$H_{2}\left(f_{0}+V_{1} / L_{1}\right)=H_{1}\left(f_{0}+V_{2} / L_{2}\right)$,

and $V_{1} H_{1} L_{1}=V_{2} H_{2} L_{2}$

leading to

$L_{2}=L_{1} \frac{H_{1}}{H_{2}} \sqrt{\frac{R o}{1+R o-H_{1} / H_{2}}}, \quad V_{2}=\frac{V_{1} H_{1} L_{1}}{H_{2} L_{2}}$

with the Rossby number $0<\mathrm{Ro}=\mathrm{V}_{1} / \mathrm{f}_{0} \mathrm{~L}_{1}<1$.

With $0<\mathrm{H}_{1} / \mathrm{H}_{2}<1$, a current with cyclonic shear narrows and accelerates when entering the canyon. This corresponds to an increase of relative vorticity to compensate vortex stretching.

For a current with anticyclonic shear, the evolution is opposite.

When the current exits the canyon, the same formula applies, now with index 1 denoting canyon values and index 2 denoting downstream values, and with $1<$ $\mathrm{H}_{1} / \mathrm{H}_{2}<\infty$. A current with cyclonic shear widens and decelerates on the western flank of the canyon to compensate vortex squeezing. But now, the bathymetric step imposes a maximum value for the current to remain zonal and to continue westward: $\mathrm{H}_{1} / \mathrm{H}_{2}=$ $1+$ Ro. For larger steps, the current cannot remain zonal: either it follows the western edge of the canyon meridionally or it transfers the excess of negative relative vorticity into a local, non-zonal perturbation (e.g. an anticyclonic eddy).

In the case of a real canyon (not a plain trench), the current can be topographically steered around the canyon rim. If the flow has a weak Rossby number, vortex stretching $\mathrm{f}_{0} / \mathrm{h}$ dominates relative vorticity in q. Here the fluid thickness $h$ is determined by the shape of the bathymetry. Since $J\left(v, f_{0} / h\right)=0$, isobaths are also transport streamlines.

Note that the same result holds with a free surface (or a free interface) for the fluid. Vortex stretching then dominates relative vorticity when the Burger number is weak. The fluid thickness is also essentially constrained by the shape of bathymetry since isopycnal deviations remain small compared with bathymetric variations. This property validates an application of this theory to the lower core of Mediterranean Water.

\subsection{Comparison with observations}

These results are now used to interpret the observed variations of the lower core of Mediterranean Water over Portimão canyon. Obviously, the model is idealized compared with reality, since it lacks stratification and the three-dimensional structure of currents and of bathymetry. But the physical principles underlying the equations are the key point here.

The northern branch of the lower core is topographically steered (figure 5c). It flows northwestward on the eastern flank of the canyon, and southwestward on its western flank. This path corresponds to the shoreward deviation of the salinity maximum inside the canyon (figure 4). It joins the southern branch west of the canyon (figure $5 d$ and $e$ ).

On the contrary, the southern part of the lower core flows across isobaths quasi zonally and crosses the canyon (figure 5b). Upstream of the canyon, this southern branch is asymmetric: the negative shear inshore is stronger than the positive shear offshore. When this branch falls into the canyon, it tends to symmetrize, i.e. the inshore part with negative shear widens and decelerates, while the offshore part narrows and accelerates (figure not shown). Since the inshore part is the fastest, this southern branch is observed to globally decelerate. This increase in cyclonic relative vorticity is obviously due to the vertical vortex stretching of the water columns; it corresponds to the strong positive potential vorticity anomaly observed near $\sigma_{1}=32.1$ at $8^{\circ} 32^{\prime} \mathrm{W}$ on figure 6.

When this branch exits the canyon, water columns are squeezed and negative relative vorticity is produced; the inshore part of this branch becomes narrower and accelerates while the offshore part widens and slows down: globally, the current accelerates and becomes asymmetric again.

Now, when entering the canyon, this southern branch is faster and more zonal in 1995 than in 1997; therefore it crosses the canyon in 1995, while in 1997 a small anticyclonic eddy is formed.

Using realistic values for our criterion, $h_{1}=1600 \mathrm{~m}$, $\mathrm{h}_{2}=1200 \mathrm{~m}$, we obtain that the critical value of the Rossby number must be Ro $=1 / 3$. With $\mathrm{f}_{0}=8.55 \cdot 10^{-5}$ $\mathrm{s}^{-1}, \mathrm{~L}=20 \mathrm{~km}$, the corresponding zonal velocity for the formation of a vortex is $\mathrm{U}=0.57 \mathrm{~m} \mathrm{~s}^{-1}$. 
Such velocities are indeed found near the western rim (see figure 5c).

Obviously, the evolution of the upper core is not described by our homogeneous model, but it can be explained physically. When the lower core forms an anticyclonic eddy in the canyon, this core becomes wider and thus more sensitive to baroclinic instability. The currents at 800 and at $1100 \mathrm{~m}$ on the eastern flank of the canyon are then southward (figure 5e). The upper core then extends offshore and aligns vertically with the lower core, reinforcing baroclinic instability.

\section{DISCUSSION AND CONCLUSIONS}

In situ data of the Semane 95 and 97 experiments evidence that the instability affecting the Mediterranean Water undercurrents at the mesoscale is particularly enhanced near topographic accidents such as capes and canyons. These topographic features can induce changes in the direction of the flow, or the formation and the detachment of filaments and eddies. In the Semane data, two anticyclonic eddies were observed near the undercurrents: a small eddy was forming in the Portimão canyon during Semane 97, while during Semane 95, a meddy lay west of Cape Saint Vincent, from which it most likely originated. Both eddies had a baroclinic structure, seen in the hydrographic data and in the trajectories of deep-drogued Surdrift buoys.

Instability of the Mediterranean Water undercurrents often occurs near capes and canyons:

- at capes, the upper core moves seaward, both cores widen and the transverse thermohaline gradient decreases. These are the results of the centrifugal force due to rotation around the cape.

- over canyons, thermohaline maxima move shoreward; a strong thermohaline gradient is often found at the offshore boundary of the cores.

The vertical alignment of the undercurrents favors their baroclinic instability (by enhancing the resonance of phase-locked Rossby waves on the vorticity fronts), but this instability is all the stronger as the fronts are sharper. Therefore, meddy formation near capes likely results from both the change in direction of the undercurrents $(\mathrm{Ou}$ and De Ruijter, 1986; Klinger, 1994; Pichevin and Nof, 1996) and from baroclinic instability.
A more detailed investigation of the undercurrents near Portimão canyon reveals that, at $8^{\circ} 20^{\prime} \mathrm{W}$, the lower core of Mediterranean Water splits into two branches separated by a topographic peak. The northern branch is strongly steered topographically and follows the northern rim of the canyon; the southern branch crosses the canyon, and forms a small eddy when the inflow at $8^{\circ} 20^{\prime} \mathrm{W}$ is weaker and directed more southward (1997 observations). Strong decrease in salinity is observed from east to west of the canyon, which can be associated with mixing or with instability.

The distribution of potential vorticity anomaly upstream, inside and downstream of the canyon, indicates that the canyon amplifies both the vertical and horizontal gradients of potential vorticity, thereby favoring both barotropic and baroclinic instabilities.

Finally, a simple stationary model illustrates the effect of potential vorticity and mass flux conservation: they lead to the symmetrization of the southern branch of the lower core when it falls into the canyon, and they show that the western flank of the canyon may appear as an obstacle to the westward progression of the lower core, creating thus an anticyclonic eddy.

Clearly, Semane 95 and Semane 97 had to achieve a compromise between large coverage, high-resolution and synopticity. This compromise does not allow as complete an analysis of the instability of the undercurrents as desired. For instance, our conclusions that the lower core plays a decisive role in the formation of small eddies in the Portimão canyon whenever the inflow is sufficiently slow and directed southwestward, could be confirmed or invalidated by repeated hydrological and LADCP sections in and around Portimão canyon. Also potential vorticity is a difficult quantity to estimate in the ocean, due to errors in measurements: further measurements at high resolution near the same location should yield error estimates for our results.

In particular, day-long CTD/LADCP stations will help remove the high-frequency motions from velocity measurements.

The Semane program continues with a double objective: 
1. characterize the perturbations of the undercurrents in the vicinity of Portimão canyon and Cape Saint Vincent, to determine under which conditions can (m)eddies form, and if unstable events at both sites are correlated. In particular, can the small eddies formed in Portimão canyon merge with the anticyclonic circulation around Cape Saint Vincent and eventually kick off a large meddy?

2. measure the large-scale zonal fluxes with a highresolution CTD/LADCP section along $8^{\circ} 20^{\prime} \mathrm{W}$ (from Portugal to Morocco). This section will help quantify the (horizontal and vertical) water mass exchanges in the Gulf of Cadiz. Such measurements can also provide precise boundary conditions to high-resolution numerical models of the North Atlantic ocean.

This program has begun with the Semane 99 cruise. During this experiment, the $8^{\circ} 20^{\prime} \mathrm{W}$ section showed a subsurface-intensified cyclonic eddy near $35^{\circ} 30^{\prime} \mathrm{N}$ accompanied by a meddy near $34^{\circ} 30^{\prime} \mathrm{N}$. A second meddy was observed further west, creating with the former two eddies a temporary tripolar structure. The part played by baroclinic instability in the formation of such a vortex compound still has to be elucidated. On this section, a 25 h-long CTD/LADCP station was performed to filter highfrequency signals from velocity measurements.

The Semane program will continue in year 2000 with the mooring of currentmeters both at Cape Saint Vincent and near Portimão canyon to establish long-term correlations between the two sites (the aspect of temporal continuity was missing in the Semane data thus far, except for drifter trajectories). Correlations of unstable events with atmospheric variability will also be performed.

Considering the cost of in-situ measurements, numerical modeling with a three-dimensional model will also be performed to assess the sensitivity of the undercurrents in the Portimão canyon to variable flow conditions upstream. The nature of the instability at this location, and in particular the predominance of baroclinic mechanisms correlated with topographic effects, will be investigated in more detail.

\section{Acknowledgements}

This research was funded under SHOM contracts FRE91009401 and PEA982407. Mr Yves Camus and Eric Duporte took an active part in designing the experiments at sea. The captains and crews of BO D'Entrecasteaux and of $\mathrm{BH} 2$ Lapérouse provided substantial help in data collection. The $\mathrm{CMO} / \mathrm{CM}$ group, $\mathrm{Mr}$ Yannick Bian and Rodolphe Rousselet processed the Semane 95 and Semane 97 data. Pr Ivan Dekeyser's support during the course of this work is acknowledged. These results are a contribution to the Semane research program.

\section{REFERENCES}

Ambar, I., Howe, M.R., 1979. Observations of the Mediterranean outflow, II: the deep circulation in the vicinity of the Gulf of Cadiz. Deep-Sea Res. 26 A, 555-568.

Bower, A.S., Armi, L., Ambar, I., 1995. Direct evidence of meddy formation off the southwestern coast of Portugal. Deep-Sea Res. I 42, 1621-1630.

Bower, A.S., Armi, L., Ambar, I., 1997. Lagrangian observations of meddy formation during A Mediterranean Undercurrent Seeding Experiment. J. Phys. Oceanogr. 27, 2545-2575.

Chérubin, L., Carton, X., Dritschel, D.G., 1996. Vortex expulsion by a zonal coastal jet on a transverse canyon. Proceedings of the 2nd Int. Workshop on Vortex Flows, ESAIM, SMAI, Paris $1,481-501$.

Chérubin, L., et al., 1997. Descriptive analysis of the hydrology and currents on the Iberian shelf from Gibraltar to Cape Finisterre: preliminary results of the INTERAFOS and SEMANE 95 experiments. Ann. Hydrograph. 21 (768), 5-69.

Hoskins, B.J., McIntyre, M.E., Robertson, A.W., 1991. On the use and significance of isentropic potential vorticity maps. Quart. J. R. Met. Soc. 111, 946-977.

Käse, R.H., Hinrichsen, H.H., Sanford, T., 1996. Inferring density from temperature via a density-ratio relation. J. Atmos. Ocean. Technol. 13, 1202-1208.

Käse, R.H., Zenk, W., 1996. Structure of the Mediterranean Water and meddy characteristics in the Northeast Atlantic. In: Krauss, W. (Ed.), The Warmwatersphere of the North Atlantic Ocean, chapter 12. Gebruder Borntraeger, Berlin, 445 p.

Klinger, B.A., 1994. Inviscid current separation from rounded capes. J. Phys. Oceanogr. 24, 1805-1811.

Madelain, F., 1970. Influence de la topographie de fond sur l'écoulement méditerranéen entre le détroit de Gibraltar et le cap Saint Vincent. Cahiers Océanographiques 22, 43-61.

Morel, Y., 1995. Étude des déplacements et de la dynamique des tourbillons géophysiques; application aux meddies. Thèse Dr. Univ. Joseph Fourier, Grenoble, France.

O'Neil-Baringer, M., Price, J.F., 1997. Mixing and spreading of the Mediterranean outflow. J. Phys. Oceanogr. 27, 1654-1677. 
Ou, H.W., De Ruijter, W.P.M., 1986. Separation of an inertial boundary current from a curved coastline. J. Phys. Oceanogr. 16, 280-289.

Paillet, J., LeCann, B., Serpette, A., Morel, Y., Carton, X., 1999. Real-time tracking of a northern meddy in 1997-1998. Geophys. Res. Lett. 26, 1877-1880.

Pichevin, T., Nof, D., 1996. The eddy cannon. Deep-Sea Res. I 43 (9), 1475-1507.

Prater, M., Sanford, T.B., 1994. A meddy off Cape St Vincent. Part I. Description. J. Phys. Oceanogr. 24, 1572-1586.

Swallow, J.C., 1969. A deep eddy off Cape St Vincent. Deep-Sea Res. 16 (suppl.), 285-295.
Tychensky, A., Carton, X., 1998. Hydrological and dynamical characterization of meddies in the Azores region: a paradigm for baroclinic vortex dynamics. J. Geophys. Res. 103 C, 25, 061-25,079.

Zenk, W., 1970. On the temperature and salinity structure of the Mediterranean Water in the northeast Atlantic. Deep-Sea Res. A $17,627-631$.

Zenk, W., 1975. On the Mediterranean outflow west of Gibraltar. Meteor-Forsch. Ergebnis. Reihe A 16, 23-34.

Zenk, W., Schultz-Tokos, K.L., Boebel, O., 1992. New observations of meddy movement south of the Tejo plateau. Geophys. Res. Lett. 12 (24), 2389-2392. 